\title{
A expansão da Universidade Federal do Amazonas: implicações a partir do financiamento em tempos de crise
}

\author{
The expansion of Universidade Federal do Amazonas: \\ implications from financing in times of crisis
}

\author{
Elizandra Garcia da Silva ${ }^{1}$ \\ ${ }^{1}$ Universidade Federal do Amazonas \\ Instituto de Ciências Sociais, Educação e Zootecnia \\ Departamento de Educação Física \\ Parintins | AM | Brasil. Contato: elizandragarcia@ hotmail.com \\ http://orcid.org/0000-0002-1580-156X
}
Resumo: Neste artigo, partimos da realidade material da expansão da Universidade Federal do Amazonas (UFAM), em curso no interior do estado, para analisar: o financiamento; o objetivo quantitativo de acesso ao ensino superior, estimado pelo governo federal; as avaliações positivas do governo federal sobre o Programa de Apoio a Planos de Reestruturação de Expansão das Universidades Federais (Reuni); e elementos inseridos no contexto da sociedade do capital em crise. Hipotetiza-se haver nexos determinantes entre o financiamento e a categorização de uma educação precarizada nos campi de expansão da UFAM, como um reflexo da conjuntura mundial de continuidade da crise do capital e as políticas de ajustes do Governo Temer para a educação superior.

Palavras-chave: Financiamento. Universidades federais. Expansão da UFAM. Crise do capital. Precarização da educação.

Abstract: In this article, we start from the material reality of the expansion of Universidade Federal do Amazonas (UFAM), ongoing in the interior of the state, to analyze: the financing; the quantitative objective of access to higher education, estimated by the federal government; the positive evaluations of the federal government on the Program to Support Restructuring Plans for the Expansion of Federal Universities (Reuni); and elements inserted in the context of the society of the capital in crisis. Our hypothesis is a determinant link between the financing and the categorization of a precarious education in UFAM's expansion camp, as a reflection of the global conjuncture of the crisis of capital continuity and the Temer Government's adjustment policies for higher education.

Key words: Financing. Federal universities. Expansion of UFAM. Crisis of capital. Precarious education.

DOI: http://dx.doi.org/10.1590/S1414-40772019000100003

Recebido em: 6 de novembro 2016

Aprovado em: 12 de setembro 2018

Este é um artigo publicado em acesso aberto (Open Access) sob a licença Creative Commons Attribution Non-Commercial, que permite uso, distribuição e reprodução em qualquer meio, sem restrições desde que sem fins comerciais e que o trabalho original seja corretamente citado. https://creativecommons.org/licenses/by-nc/4.0/ 


\section{Introdução}

No presente estudo, buscamos analisar a expansão da Universidade Federal do Amazonas (UFAM) e, em particular, a maneira como o financiamento destinado a cada um dos cinco campi de expansão tem interferido na conclusão e consolidação do Programa de Apoio a Planos de Reestruturação de Expansão das Universidades Federais (Reuni) ${ }^{1}$ e na qualidade da educação superior para o interior do Amazonas (BRASIL, 2007).

A expansão da UFAM, assim como das demais universidades federais brasileiras, é uma das medidas do Reuni, no sentido de proporcionar uma ramificação ao interior (LIMA; MACHADO, 2016). No estado do Amazonas, buscou-se atingir, em duas etapas, as cidades de Benjamin Constant, Coari, Humaitá, Itacoatiara e Parintins (CARNEVISKIS; MACALINI; SILVA, 2016).

Apesar de o governo federal, por meio de seus designados, ter publicado avaliação positiva do processo de expansão, em 2012, o estudo do estado da arte desse temário, evidenciaram pesquisas com resultados discrepantes dos oficiais publicados pelo Ministério da Educação (MEC). Por meio desses estudos foi possível compreender a expansão do ensino superior no bojo do projeto de reestruturação do capital mundial, a partir da incorporação, por parte do governo brasileiro, das políticas emanadas do Banco Mundial, agencia multilateral de financiamento que não tem esse nível de ensino como prioritário (BASTOS, 2009; PAULA, 2009; SILVA, 2014).

Nesse contexto, não se verificam tais êxitos quantificados pelo MEC na realidade material encontrada na expansão da UFAM. As contradições identificadas impulsionaram a construção de um estudo que nos deu subsídios para compreender que a expansão da UFAM não se constitui em um fenômeno isolado; ao contrário, insere-se na totalidade do programa Reuni e está em relação com as transformações da sociedade do capital, em especial com a crise, a reestruturação produtiva e os ajustes estruturais do Estado neoliberal. Desse modo, entendemos que somente a partir de tal análise é possível tecer uma resposta ao problema desta pesquisa: quais são as implicações do financiamento no programa de expansão na UFAM?

No bojo das contradições que se apresentaram à construção da resposta para essa questão, ocupamo-nos com as análises dialéticas entre a crise mundial da estrutura do capital de 1970 - por se constituir no núcleo desencadeador dos ajustes estruturais e da reestruturação

\footnotetext{
${ }^{1}$ Programa iniciado pelo governo federal em 2007.
} 
da produção, com o intuito de retomar o crescimento e o acúmulo do capital, o que interferiu diretamente nas transformações ocorridas no Brasil e na educação brasileira a partir da década de 1990 - e como apontaram alguns estudos consultados, a crise de 2007/2008, da qual o capital ainda busca recuperação (CARNEVISKIS; MACALINI; SILVA, 2016).

A fim de recuperar o crescimento econômico, implementaram-se no Brasil a reestruturação produtiva e os ajustes estruturais, determinando-se o Estado neoliberal como modelo a ser seguido. Por conseguinte, estabeleceu-se como prioridade atender os setores privados, em detrimento dos setores públicos, como ocorreu com a educação - e em especial a educação superior, objeto deste estudo (BASTOS, 2009; ANDRADE, 2013).

Além da determinante crise estrutural de 1970, é necessário registrar que a recessão econômica e o colapso da política foram justificativas universais utilizadas pelos governos para a não consolidação do Reuni, causando prejuízos na aplicação deste programa nas universidades federais, como observamos no caso concreto da UFAM.

Contudo, se analisarmos o projeto inicial do Reuni e a avaliação positiva realizada pelo Ministério da Educação em 2012, mesmo com os cortes orçamentários já em curso desde 2008, temos subsídios para afirmar que houve rompimento no processo de consolidação, e mesmo com essa interrupção os índices numéricos de acesso à educação superior foram alcançados. Identificando esse fenômeno asseveramos que a avaliação positiva é expressiva do quantitativo de acesso e não da qualidade da permanência, consolidação da expansão e fortalecimento da universidade pública (BRASIL, 2012; CARNEVISKIS; MACALINI; SILVA, 2016).

Apesar de nesse período as universidades públicas terem crescido menos do que as instituições privadas, o processo de expansão representou um marco na oferta de vagas no ensino superior público. Todavia, dita expansão não se deu de forma qualitativa, ao contrário. De acordo com Zago, Pereira e Paixão (2015, p. 4), "há uma expansão da rede de ensino superior que visa à massificação do sistema", consolidada sobre as bases quantitativas de números de matrículas e na relação da quantidade de alunos para cada professor - assertiva verificada na expansão instaurada no Amazonas (MANCEBO; VALE; MARTINS, 2015).

Ao priorizar a quantidade e não a qualidade da educação superior pública, a UFAM iniciou sua expansão com 30 cursos de graduação, posteriormente ampliados para $32 . \mathrm{Na}$ primeira etapa, com previsão orçamentária ${ }^{2}$ para 2007, foram criados os campi de Benjamin

\footnotetext{
${ }^{2}$ A primeira inserção dos campi de expansão da UFAM na Lei Orçamentária Anual (LOA) ocorreu em 2007.
} Retomaremos essa discussão adiante. 
Constant $^{3}$, Coari ${ }^{4}$ e Humaitá ${ }^{5}$. Na Lei Orçamentária Anual (LOA) de 2008, foram criados os campi de Itacoatiara ${ }^{6}$ e Parintins ${ }^{7}$.

O financiamento inicial priorizava a construção da estrutura física e material para alocar as atividades de ensino, pesquisa e extensão, que estavam sendo realizadas em espaços cedidos em escolas, igrejas, sedes de associações de bairros, praças, fazendas, entre outros locais. Todavia, como observaremos, o financiamento inicial não foi assegurado até que se finalizasse a construção e a consolidação dos campi de expansão. Ao contrário, a partir do segundo ano do projeto, quando ainda não haviam sido construídas nem as salas de aulas, o orçamento passou a sofrer constantes cortes, que vêm sendo realizados até a atualidade, impossibilitando a conclusão do programa.

É de se observar, entretanto, que a redução no orçamento direto para o programa de expansão não foi a única responsável pelas condições precárias em que se realiza a educação superior nesses campi. Essa contenção expressou-se desde a diminuição de quase $50 \%$ do custo por aluno na previsão orçamentária, que em 10 anos caiu de $\mathrm{R} \$ 9,7$ mil para $\mathrm{R} \$ 5$ mil. Com os cortes orçamentários justificados na crise atual, o custo por aluno tende a decrescer ainda mais para os próximos períodos (LEHER, 2010).

No rol dos ajustes financeiros, não foi apenas a estrutura física e material que deixou de ser consolidada, mas também os recursos humanos, em especial docentes e técnicos administrativos. Estes profissionais não atendem às necessidades impostas pelo quantitativo de trabalho e se sujeitam a extrapolar a carga horária de trabalho semanal, ou deixam de assumir atividades de pesquisa e extensão, em detrimento das atividades de ensino, para que os cursos continuem em andamento.

A constante redução do financiamento tem inviabilizando a consolidação mínima do programa de expansão das universidades públicas, assim como na UFAM, determinando

\footnotetext{
${ }^{3}$ Cursos: Administração em Gestão Organizacional, Antropologia, Ciências Agrarias e do Ambiente, Ciências: Biologia e Química, Letras e Pedagogia.

${ }^{4}$ Cursos: Biotecnologia, Ciências: Biologia e Química e Ciências: Matemática e Física, Enfermagem, Fisioterapia e Nutrição.

${ }^{5}$ Cursos: Agronomia, Ciências: Biologia e Química e Ciências: Matemática e Física, Engenharia Ambiental, Letras e Pedagogia.

${ }^{6}$ Cursos: Agronomia, Ciências Farmacêuticas, Ciências: Biologia e Química e Ciências: Matemática e Física, Engenharia de Produção, Engenharia Sanitária, Engenharia de Software, Química Industrial e Sistemas de Informação.

${ }^{7}$ Cursos: Administração em Gestão Organizacional, Artes Visuais, Comunicação Social, Educação Física, Serviço Social, Zootecnia e Pedagogia.
} 
condições precárias de trabalho e estudo para docentes, técnicos administrativos em educação (TAE) e estudantes (MAUÉS; SOUZA, 2015). Na expansão da UFAM,essas condições se agravam em proporções amazônicas, em observância às particularidades de cada uma das cinco cidades para as quais a universidade se expandiu. São fundantes desse agravamento as distâncias geográficas do campus sede (Manaus), muitas vezes ferindo o princípio da isonomia entre docentes, TAE e estudantes da sede e dos campi de expansão.

Com o agravamento da crise e as recentes políticas do Governo Temer para a educação e educação superior, a grande preocupação que ronda os campi de expansão é que - por falta de financiamento adequado para conclusão, consolidação e funcionamento, e em cumprimento a Emenda Constitucional 95/2016, à Portaria Normativa no 20 de 13 de outubro de 2016, e à Reforma da Previdência - se aprofunde tanto a precarização da educação na UFAM que esta deixe de existir, como se fosse mais uma Lenda Amazônica (BRASIL, 2016a, 2016b).

\section{A crise de 1970 e a crise atual: reestruturação produtiva do capital, ajustes estruturais e educação}

O modo de produção capitalista, enquanto sistema sociometabólico do capital, vem passando por profundas transformações, em especial a partir de 1970, as quais buscamos identificar e mediar, em sua extensão, para a esfera da educação (ANTUNES, 2003; MÉSZÁROS, 2002). Atentaremos neste estudo para as transformações ocorridas a partir de 1970, por ser este o marco da crise $^{8}$ do sistema, e os anos seguintes, como início da reestruturação produtiva do capital e dos ajustes estruturais ocorridos no Estado neoliberal, e que determinaram transformações na educação (MÉSZÁROS, 2002).

Essas transformações são produto de contradições no seio do próprio sistema econômico capitalista.Como já sinalizou Marx no decorrer de sua obra, e por vezes em companhia de Engels ${ }^{9}$, a acumulação do capital só pode ocorrer por meio de crises da interrupção periódica da acumulação de capital.

\footnotetext{
${ }^{8}$ Quanto à importância sócio-histórica do pensamento marxengelsiano sobre as crises do capital, acreditamos ser importante pontuar as tendências elencadas pelos autores: a análise da crise no processo de circulação das mercadorias; a análise da crise no âmbito do processo de produção; a análise da crise no âmbito da valorização da mais-valia; e a apropriação individual do valor.

${ }^{9}$ Quando esse autor desenvolve a origem da família, da propriedade privada e do Estado, atém-se aos fundamentos primordiais dessas instituições, sendo sua releitura para a sociedade moderna presente em suas demais produções e em suas parcerias com Marx.
} 
A partir desses apontamentos,embasamo-nos nos autores marxianos, os quais evidenciaram que as transformações ocorridas a partir da década de 1970são o resultado de uma crise sistêmica da sociedade do capital, sendo o padrão de acumulação taylorista-fordista incapaz de assegurar uma retomada do eixo cíclico de crescimento e superação da Queda Tendencial da Taxa de $\operatorname{Lucros}^{10}$, conforme categorizou Marx (1978). O autor asseverou ser essa uma tendência e não uma lei, logo alguns dispositivos podem ser acionados pelo capital para a restituição da acumulação, porém nunca nos padrões acumulados anteriormente, e sim em padrões sempre inferiores.

Em resposta à agudização da crise estrutural, o capital desencadeou uma reestruturação dos modais de produção de mercadorias, com profundas transformações no mundo do trabalho e extensão na exploração dos bens naturais como matéria-prima, inseridos no que Marx categoriza como capital constante (ANTUNES, 2003). Com o intuito da reestruturação produtiva, o capital transferiu o modelo de produção do taylorista-fordista para o toyotista, pautado na acumulação flexível e impactante ao mundo do trabalho e à educação (NOZAKI, 2004).

Dentre os impactos, Antunes (2001) indicou a crescente redução do proletariado fabril estável, o enorme incremento do novo proletariado (terceirizados e subcontratados), o aumento do trabalho feminino (trabalho precarizado e desregulamentado) e o incremento dos assalariados médios e de serviço. Para cumprir com o novo formato do trabalho, foi necessário um trabalhador de um novo tipo, polivalente, capaz inclusive de cooperar em projetos de máquinas e na gestão da qualidade dos produtos.

Essa necessidade de o capital ter um novo tipo de trabalhador indicou mudanças para a educação. Os estudos de Ramos (2011) foram fundamentados sob a tese de que no modelo flexível de produção houve um deslocamento conceitual de formação para o trabalho para a qualificação ${ }^{11}$ ou formação de competências requisitadas pelo mercado. Esse deslocamento foi estendido para os documentos que regem a educação brasileira, como por exemplo a Lei de Diretrizes e Bases (LDB), os Parâmetros Curriculares Nacionais da Educação Básica (PCN) e as Diretrizes Curriculares (DC) dos cursos de graduação, reformadas desde 2003 e sobre as quais se assentaram os cursos do Reuni (BRASIL, 1996, 2000, 2003).

${ }^{10}$ É possível aprofundamento dessa Lei nos capítulos 13 e 14 do Livro III de O Capital.

${ }^{11}$ A compreensão da autora acerca da qualificação é no campo da relação social. 
Conservamos o pensamento marxiano para entendermos que a crise do capital, apesar de generalizada por todo o sistema, não se deu da mesma forma em nível mundial. Os estudos de Antunes e Silva (2010, p. 10) auxiliaram nessa compreensão, ao afirmarem que o desenvolvimento das forças produtivas e do capital, apesar de global e mundializado, encontra particularidades, em contradições bastante acentuadas. Esses autores alertaram que, "por trás de aparente hegemonia e universalidade de situações", há diferenças entre os países "ricos e pobres, centrais e subordinados, e também no interior dos mesmos". No bojo dessas peculiaridades, em leitura dialética com as questões mais ampliadas, situamos o desenvolvimento desigual do Reuni na UFAM, e em cada um dos campi de expansão, pois, além de economicamente distintos, estão localizados em municípios distantes entre si e da capital $^{12}$.

Considerando as especificidades regionais, Sader e Gentili (1995) situou historicamente que, no Brasil, a crise do capital iniciou aproximadamente em meados da década de 1980 e se aprofundou na década de 1990. Além da mudança do modelo sob o qual se produz, a reestruturação produtiva constituiu-se também de redução da força de trabalho.À medida que necessitaram elevar a produtividade, as empresas ancoraram-se na maior exploração da maisvalia, associadas ao início da implementação dos Círculos de Controle de Qualidade e dos sistemas Just in time e Kanban, presentes em empresas da Região Amazônica, que exploram também a força de trabalho de trabalhadores do interior do estado, inclusive formados pelos campi de expansão da UFAM (MOURÃO, 2006).

A associação desse novo modo de produção do capital aos governos neoliberais de Fernando Collor de Melo e Fernando Henrique Cardoso postergou para a década de 1990 sua intensificação, que se prolongou com a abertura econômica, privatizações, injeção de verbas estatais em empresas privadas - inclusive na educação privada - e financeirização da economia (NOZAKI, 2004). Essa abertura econômica e a privatização das empresas estatais vêm refletir diretamente no âmbito educacional, que se orienta por direções internacionais do capital, em especial as agências multilaterais de financiamento, como o Banco Mundial, por meio de tratados e acordos, bem como na ampliação das metas e planos assumidos pelos distintos ministérios e pela política nacional de desenvolvimento.A educação pública brasileira

${ }^{12}$ Entre os campi de expansão, há outras peculiaridades, mas nos deteremos a estas, devido à proximidade com o objeto estudado. 
continuou ocorrendo como parte do mesmo projeto neoliberal de Estado, nos governos de Lula, Dilma e Temer, com o Reuni, o Prouni e o Fies.

Com o início da aplicação da cartilha neoliberal na década de 1990, dois aspectos fundamentais impactaram o Estado (NOZAKI, 2004) se, por um lado, passou a ser mínima a interferência estatal para as questões públicas, por outro, houve a incorporação dos ditames do Banco Mundial para a educação, em especial a educação básica e para o trabalho ${ }^{13}$. Este último efeito é observado em todos os âmbitos e níveis educacionais, inclusive na universidade. Nesta, vêm sendo enfatizadas as áreas tecnológicas, em detrimento em especial das licenciaturas, que passaram a ter, a partir das Reformas Curriculares de 2003, cargas horárias rebaixadas para o funcionamento dos cursos, atendendo aos critérios mínimos da educação básica, com um deslocamento para a formação das competências (BANCO MUNDIAL, 1995; SADER; GENTILI, 1995, 1999; BRASIL, 2003).

Além dessas transformações neoliberais, a educação passou a ser direcionada pelo projeto hegemônico capitalista. Solano e Costa (2011, p. 11) compreenderam em seus estudos que essa nova formatação "objetiva uma educação instrumental sob a retórica de 'novo homem', apto às inovações sociais, flexível, criativo, empreendedor, solidário [...]”.

Nos governosdo Partido dos Trabalhadores, além da permanência da aceitação dos ditames do Banco Mundial para a educação básica, Lula e Dilma decidiram pela expansão quantitativa do ensino superior, elevando os números de matrículas em mais de $110 \%$ (BRASIL, 2012). Todavia, com a permanência da crise do capital de 2007/2008 e a manutenção de níveis de acumulação menores do que no momento anterior, o Estado passou a desempenhar maiores ajustes, em especial para cumprir com a agenda da dívida externa:se em 2001, a dívidarepresentava 75\% do PIB de cada país endividado, em 2014 passou a representar mais de $118 \%$. Esse dado auxilia na compreensão dos cortes orçamentários ao programa de expansão, impedindo sua consolidação e culminando nos processos de precarização vivenciados por todas as expansões universitárias. Em 2015, início da recessão econômica, os cortes foram ainda mais profundos e diminuíram o orçamento para os campi de expansão da UFAM em 30\%; o que não representa um fenômeno isolado, mas é parte dos ajustes realizados, que totalizaram um bilhão de reais para a educação (ZAGO; PEREIRA; PAIXÃO, 2015; COMPARATO, 2015).

\footnotetext{
${ }^{13}$ A noção de empregabilidade está presente nos ditames do Banco Mundial; aquisição das competências, inclusive as estabelecidas para a educação básica, é compreendida como mediação para o trabalho.
} 
Além da não consolidação dos campi de expansão, e em cumprimento ao caráter neoliberal, Michel Temer tem assumido políticas mais incisivas de ajustes na educação e priorizado a subserviência do Estado ao capital financeiro nacional e internacional. Desde que assumiu o governo, o atual presidente tem realizado ajustes que ameaçam e fragmentam o Programa de Iniciação à Docência (Pibid) e que já incidiram em corte de bolsas do Programa Institucional de Bolsas de Iniciação Científica (Pibic), e na impossibilidade das licenciaturas com notas baixas nas avaliações adentrarem a concorrência aos editais, como ocorrido recentemente em alguns cursos da UFAM, contribuindo para o agravamento da precarização. Uma ameaça ainda maior às licenciaturasse constitui na reforma do ensino médio, que faculta alguns dos componentes curriculares como Educação Física e Artes.

O pacote de ajustes não se finda nessas políticas: somadas a elas foi aprovada a Emenda Constitucional 95/2016, que cria teto para os gastos públicos por até 20 anos, incluídos saúde, segurança pública, e educação. A justificativa governamental emergiu da crise econômica brasileira, amparada pela possibilidade de tal emenda viabilizar equilíbrio fiscal para atrair investimentos privados. Tal Emenda não alcançou o objetivo de recuperação da crise econômica e interferiu negativamente no financiamento dos serviços públicos essenciais como educação, segurança pública e saúde ${ }^{14}$.

Retomando a particularidade da expansão do ensino superior, e considerando a implementação da Emenda Constitucional 95 compreendemos importante registrar a eminencia da não consolidação do projeto de expansão previsto em 2007. Essa preocupação é latente no âmbito das universidades, sendo partilhada pelos dirigentes das Instituições de Ensino Superior/IES em audiência pública, que, entre os principais problemas pautou a falta de orçamento, e de recursos humanos e de infraestrutura, que estão inviabilizando a qualidade da educação superior do país. Além de não haver qualidade no ensino, há prejuízos na realização da extensão e da pesquisa, dissociando o sustentáculo da universidade pública: ensino, pesquisa e extensão.

Em complemento ao que entendemos como primeiro pacote dos ajustes de Temer, soma-se a Normativa $\mathrm{n}^{\mathrm{o}} 20$, de 13 de outubro de 2016, que dispõe sobre a redução de vagas para cursos de graduação das universidades federais. Possivelmente, tal medida incidirá no fechamento de cursos da expansão, pois o quadro de docentes ainda é insatisfatório e se

${ }^{14}$ Há previsão legal punitiva para o descumprimento na Emenda: proibição de contratação de servidores, não realização de reajustes salariais, não realização de concursos públicos, dentre outras. 
constitui em um dos fatores que obrigam os professores a cumprir jornadas semanais que ultrapassam 60 horas, precarizando sem precedentes seu trabalho.

O projeto neoliberal, todavia, não foi e nem está sendo aplicado sem a ocorrência de contrapontos; ao contrário, tem enfrentado resistência dos trabalhadores, juventude e do povo, conforme registrado nos escritos de Saviani (2007), temporalmente delimitado pelas décadas de 1980 e 1990. Essa resistência permanece inscrevendo o embate histórico entre os interesses de classe: de um lado, os capitalistas e seus projetos de defesa do sistema sociometabólico do capital, inclusive o projeto neoliberal de Estado; do outro, os trabalhadores, a juventude e o povo que dispõe de suas forças em defesa de uma sociedade sem classes e por um projeto de educação.

Como síntese dessa luta, desde a década de 1980, no campo da educação, foi elaborado e vem sendo constantemente atualizado, majoritariamente por professores, alunos e pais de alunos, o projeto de educação da classe trabalhadora (SAVIANI, 2007). O objetivo essencial da luta travada esteve no projeto de educação necessária para os filhos dos trabalhadores. E, ao nos embasarmos na categoria de formação humana de Ramos (2011), pudemos entender que o referente objeto atende apenas a uma necessidade transitória.Afinal, de acordo com Mészáros (2008) a reformulação na educação não pode ser concebida sem que o contexto social seja também transformado, já que para atender a uma formação humana concreta se faz necessária a transformação da sociedade, e assim o resgate do ser humano omnilateral.

\section{O financiamento para a expansão da Universidade Federal do Amazonas}

O Programa de Apoio a Planos de Reestruturação e Expansão das Universidades Federais (Reuni) da Universidade Federal do Amazonas (UFAM), assim como ocorreu com a totalidade do Reuni brasileiro, seguiu a lógica neoliberal das políticas educacionais implementada pelo governo federal, iniciadas por Fernando Henrique Cardoso, tendo continuidade e implementação nos governos Lula, Dilma ${ }^{15}$ e Temer (LIMA; MACHADO, 2016).

Seguindo tais premissas, os dirigentes reafirmaram a posição estatal em defesa da reestruturação produtiva e dos ajustes de estrutura, especialmente a partir dos ditames do Banco Mundial (1995). Para a incorporação dessas imposições ao Estado brasileiro, foi estimado, já

\footnotetext{
${ }^{15}$ Coube registrar, que, em breve avaliação dos governos do PT houveram concessões às reivindicações do capital: cortes no orçamento, privatizações, junto a escândalos e corrupção.
} 
no Plano Nacional de Educação de 2001, que a educação superior deveria atingir $30 \%$ das matrículas de jovens de 18 a 24 anos até 2010, quantitativo não alcançado mesmo com o Reuni.Como demonstraram Maués e Souza (2015), o Brasi $1^{16}$ chegou a expansão com a porcentagem de 27,8 - ou seja, não atingiu a quantidade proposta, nem valorizou aspectos relativos à própria qualidade da educação (BRASIL, 2001).

O Reuni "tinha como objetivo principal criar condições para a ampliação do acesso e permanência na educação superior, no nível de graduação presencial ${ }^{17 \%}$, em cumprimento aos ditames quantitativos do Banco Mundial (BRASIL, 2012, p. 11). Analisando a partir desse objetivo principal, é possível compreender porque a comissão ${ }^{18}$ formada pelo MEC imprimiu parecer positivo para o programa de expansão, pois houve ampliação no acesso ao ensino superior, nos 332 campi universitários, sendo que 268 desses campi se constituem em unidades fora da sede, inclusive na UFAM, com a abertura de 1.532 novas vagas (UFAM, 2015a).

Essas novas vagas do programa foram designadas aos campi de cinco cidades do interior do estado, em duas etapas: no ano de 2006, a expansão se deu para Benjamin Constant, Coari e Humaitá, ainda em estruturas improvisadas, como igrejas, escolas e salões comunitários. Nesse ano, foram implementados seis cursos de graduação em cada um desses campi, porém sem previsão de destinações financeiras/orçamentárias e com quantitativos diferentes de abertura de vagas - em Benjamin Constant, foram efetivadas 299 matrículas, enquanto em Coari foram 263, e em Humaitá, 300 (UFAM, 2016).

Em 2007, ao mesmo tempo em que passou a haver previsão orçamentária para os três primeiros campi implantados, outras duas cidades foram atendidas, Parintins e Itacoatiara, com 307 e 313 vagas, respectivamente. Estabelecido o quantitativo da expansão, passaram a ser designadas as previsões da Lei Orçamentária Anual (LOA).Os valores foram destinados de forma específica entre custeio e investimento para compra de equipamentos para a estruturação, sendo os seguintes valores em 2007:

\footnotetext{
${ }^{16}$ Permanecendo atrás de outros países da América Latina, como a Argentina, o Chile e o Panamá, por exemplo.

${ }^{17}$ Por não se constituir em objeto desse estudo, não adentraremos a discussão da educação a distância.

${ }^{18}$ Dirigentes das Instituições Federais de Ensino Superior (Andifes), dois representantes da União Nacional dos Estudantes (UNE), dois representantes da Associação Nacional de Pós-Graduandos (ANPG) e dois representantes da Secretaria de Educação Superior do Ministério da Educação (Sesu), todos com relações políticas com o governo - motivo pelo qual é possível registrar interferência direta na avaliação positiva realizada.
} 
Quadro 1 - Dados quantitativos da expansão na LOA de 2007

\begin{tabular}{|c|c|c|c|c|c|}
\hline Campi & $\begin{array}{c}\text { Previsão na LOA } \\
(\mathbf{R} \$)\end{array}$ & Custeio (R\$) & $\begin{array}{c}\text { Investimento em } \\
\text { estrutura (R\$) }\end{array}$ & Vagas & Cursos \\
\hline $\begin{array}{c}\text { Benjamin } \\
\text { Constant }\end{array}$ & $3.712 .300,00$ & $1.954 .364,00$ & $1.757 .936,00$ & 317 & 6 \\
\hline Coari & $4.144 .080,00$ & $2.023 .656,00$ & $2.120 .424,00$ & 278 & 6 \\
\hline Humaitá & $3.908 .240,00$ & $2.016 .950,00$ & $1.891 .290,00$ & 317 & 6 \\
\hline Parintins & - & - & - & 307 & 6 \\
\hline Itacoatiara & - & - & - & 313 & 6 \\
\hline
\end{tabular}

Fonte: UNIVERSIDADE FEDERAL DO AMAZONAS - UFAM. LOA 2007. Disponível em: https://ufam.edu.br/pro-reitorias/pro-reitoria-de-planejamento-e-desenvolvimento-institucional-proplan. Acesso em: 20 dez. 2015b.

No ano de 2008, a LOA objetivou previsão orçamentária para os cinco campi, porémobserva-se que, apesar de a expansão estar em pleno curso e os primeiros prédios terem sido finalizados apenas em 2009, já houve diminuição no orçamento em aproximadamente um milhão de reais para cada um dos campi contemplados no ano anterior. Mesmo com a significativa redução do orçamento, foram diminuídas apenas entre cincoe 11 vagas,permanecendo em funcionamento os seis cursos de graduação.

Quadro 2 - Dados quantitativos da expansão na LOA de 2008

\begin{tabular}{|c|c|c|c|c|c|}
\hline Campi & $\begin{array}{c}\text { Previsão na LOA } \\
(\mathbf{R} \$)\end{array}$ & Custeio $(\mathbf{R} \mathbf{\$})$ & $\begin{array}{c}\text { Investimento em } \\
\text { estrutura (R\$) }\end{array}$ & Vagas & Cursos \\
\hline $\begin{array}{c}\text { Benjamin } \\
\text { Constant }\end{array}$ & $2.880 .126,00$ & $1.160 .126,00$ & $1.720 .000,00$ & 306 & 6 \\
\hline Coari & $3.008 .615,00$ & $1.308 .615,00$ & $1.700 .000,00$ & 273 & 6 \\
\hline Humaitá & $2.974 .138,00$ & $1.249 .138,00$ & $1.725 .000,00$ & 304 & 6 \\
\hline Parintins & $5.160 .126,00$ & $1.160 .126,00$ & $4.000 .000,00$ & 311 & 6 \\
\hline Itacoatiara & $5.249 .138,00$ & $1.249 .138,00$ & $4.000 .000,00$ & 302 & 6 \\
\hline
\end{tabular}

Fonte: UNIVERSIDADE FEDERAL DO AMAZONAS - UFAM. LOA 2007. Disponível em: https://ufam.edu.br/pro-reitorias/pro-reitoria-de-planejamento-e-desenvolvimento-institucional-proplan. Acesso em: 20 dez. 2015 b.

Consideramos importante resgatar, da introdução deste estudo, as distâncias amazônicas e a não consideração destas na previsão orçamentária, o que é de essencial importância, pois o custo para a manutenção das estruturas físicas e materiais é maior quanto mais distante foi o campus da sede. Também é possível questionar a existência de campus prioritários, pela proximidade e pelos cursos oferecidos, como é o caso de Itacoatiara, que possui acesso por estrada a Manaus e sedia cursos nas áreas tecnológicas. Em observância a essas questões, em 2008, para o custeio de aproximadamente 300 estudantes, Benjamin Constant, distante 1.120 quilômetros de Manaus, teve orçamento menor que Humaitá e Itacoatiara, distantes 591 e 176 
quilômetros da capital, respectivamente ${ }^{19}$. Parintins, com maior número de alunos matriculados e distante 369 quilômetros de Manaus, teve o menor custeio ${ }^{20}$.

Em torno da mesma constante de corte orçamentário implementado para Benjamin Constant, Coari e Humaitá, em 2009 houve cortes no orçamento para todos os campi, em especial os de Parintins e Itacoatiara, também no início do processo expansivo. Quanto a Parintins, podemos identificar que diminuiu de $\mathrm{R} \$ 5.160 .126,00$, em 2008, para $\mathrm{R} \$$ 1.974.438,00, em 2009. No contexto de criação do curso de Artes Visuais, ou seja, com a abertura de mais 30 novas vagas, totalizando 330 acadêmicos, o financiamento foi reduzido e até a atualidade não foi construída sequer uma sala de aula para esse último curso.

Em Itacoatiara, apesar de terem permanecido os seis cursos iniciais, o orçamento foi reduzido de $\mathrm{R} \$ 5.249 .138,00$ para $\mathrm{R} \$ 2.112 .981,00$, não distante da realidade dos demais, que apresentaram os seguintes repasses:

Quadro 3 - Dados quantitativos da expansão na LOA de 2009

\begin{tabular}{|c|c|c|c|}
\hline Campi & Previsão na LOA (R\$) & Vagas & Cursos \\
\hline Benjamin Constant & $2.151 .311,00$ & 300 & 6 \\
\hline Coari & $2.171 .398,00$ & 262 & 6 \\
\hline Humaitá & $2.230 .895,00$ & 290 & 6 \\
\hline Parintins & $1.974 .438,00$ & 330 & 7 \\
\hline Itacoatiara & $2.112 .981,00$ & 300 & 6 \\
\hline
\end{tabular}

Fonte: UNIVERSIDADE FEDERAL DO AMAZONAS - UFAM. LOA 2007. Disponível em:

https://ufam.edu.br/pro-reitorias/pro-reitoria-de-planejamento-e-desenvolvimento-institucional-proplan. Acesso em: 20 dez. 2015b.

Após 2009, os valores destinados àexpansão foram estimados num montante único, o que impossibilitou analisar a destinação orçamentária de cada um dos campi. Apesar de não haver esses dados individualizados dos cortes orçamentários nesse breve período, angariamos informações após a diminuição de gastos realizada pelo governo federal para a educação em 2015. Esses cortes chegaram a quase 50\% do orçamento de 2009 no caso de Humaitá, e novamente o menos atingido foi Itacoatiara, possuindo os demais os seguintes financiamentos:

\footnotetext{
${ }^{19}$ Vale registrar que ambas possuem acesso via terrestre a duas capitais - de Rondônia e do Amazonas.

${ }^{20}$ Distâncias medidas em linha reta, uma vez que Humaitá, Coari e Parintins não possuem acesso via terrestre à sede da UFAM, em Manaus.
} 
Quadro 4 - Destinação orçamentária em 2015

\begin{tabular}{|c|c|c|c|}
\hline Campi & Valores orçados & Número de alunos & Número de cursos \\
\hline Benjamin Constant & $1.583 .032,42$ & 269 & 6 \\
\hline Coari & $1.319 .991,14$ & 261 & 6 \\
\hline Humaitá & $1.303 .694,74$ & 259 & 6 \\
\hline Parintins & $1.497 .140,70$ & 332 & 7 \\
\hline Itacoatiara & $1.836 .213,73$ & 379 & 7 \\
\hline
\end{tabular}

Fonte: Gestão administrativa. Disponível em: https://ufam.edu.br/pro-reitorias/pro-reitoria-de-planejamento-edesenvolvimento-institucional-proplan. Acesso em: 18 out. 2015.

A partir das análises dos dados financeiros, foi possível compreender o motivo de o Reuni não ter sido minimamente concluído na Universidade Federal do Amazonas. Além disso, tais dados legam subsídios para o entendimento da qualidade de educação que está sendo oferecida por esses campi, a iniciar pelas condições do trabalho docente, o qual categorizamos como precarizado, tomando de empréstimo a categoria de Antunes (2001). Com o trabalho docente precarizado, a qualidade da educação é diretamente atingida e já sinaliza esgotamento, exemplificado nas avaliações negativas realizadas pelo MEC para o reconhecimento dos cursos (MORAES, 2013; CARNEVISKIS; MACALINI; SILVA, 2016)

Além dos docentes, os técnicos administrativos em educação (TAE) também são acometidos de sobrecarga de trabalho, pela falta de concursos públicos ou pela extinção de cargos. Para remediar a falta de TAE, estão sendo contratados serviços terceirizados, no âmbito de toda a UFAM, que consomem mais de $50 \%$ do orçamento na expansão, uma vez que esses contratos são quitados com o financiamento de cada campus, e não pela universidade como um todo.

A situação dos estudantes se inclui nessa realidade.Embora sejam os destinatários do alcance quantitativo estabelecido pelo programa de expansão, a eles não estão sendo oferecidas as políticas de permanência necessárias, instituídas na assistência estudantil, que viabilizaria a continuidade dos estudantes na universidade. Nesse bojo, identificamos que nenhum campus de expansão possui restaurante universitário, casa do estudante e equipe de atendimento multidisciplinar. A situação agravou-se em 2016, com o drástico corte das bolsas de Programa de Bolsas de Iniciação Científica (Pibic), e tende a piorar para os estudantes de licenciatura e os das regiões dos campi, que dependem das bolsas moradia e permanência ameaçadas pela redução do financiamento para a educação - como se encontra o Programa de Iniciação à Docência (Pibid) e as bolsas moradia e permanência, que podem ser atingidas a qualquer momento.

Os estudos de Leher (2010) lembraram que alguns cortes realizados para a educação superior foram estabelecidos a partir da diminuição de $50 \%$ do custo por aluno, estabelecido 
quando da criação do programa de expansão. É expressão desses cortes de financiamento o não estabelecimento das políticas de permanência, fatores motivantes dos níveis consideráveis de evasão dos estudantes, ultrapassando quantitativos, por exemplo, de $8 \%$ nos cursos de Administração e Educação Física, de $13 \%$ no curso de Serviço Social e de $15 \%$ no curso de Pedagogia, em 2011 no campus de Parintins (UFAM, 2015a) ${ }^{21}$.

A partir da avaliação dos cortes orçamentários e das suas implicações na falta de conclusão e consolidação do programa de expansão, e por isso as condições materiais em que docentes, TAE e discentes estão realizando a educação superior nos campi de expansão, afirmamos que a educação do Reuni na UFAM, assim como de muitas outras universidades brasileiras, se constitui numa educação precarizada - ao contrário do que indicam os dados de acesso exclusivamente quantitativos.

No contexto da crise econômica e política atuais, sinalizamos o aprofundamento da precarização da educação superior da expansão da UFAM e o possível esgotamento de alguns cursos nos campi, pois não conseguirão sobreviver com a aprovação da EC 95/2016, que legisla prevendo congelamento dos investimentos na educação por 20 anos. Ou seja, a estrutura física e material continuará inconclusa e será desgastada pelo uso de 20 anos sem manutenção. Somado ao congelamento, assombra ainda o fechamento dos concursos públicos para docentes e TAE, que são necessidades latentes na expansão, pela peculiaridade da dificuldade de fixação desses trabalhadores da educação por falta de políticas para áreas de difícil acesso, como se constitui a maioria das cidades em que se estabeleceram os campi.

Diante dessa conjuntura, afirmamos que a tendência, caso as políticas de Temer e seus aliados não sejam barradas, é a UFAM no interior do Amazonas ser somada às variadas lendas já existentes na região. Contudo, diferentemente das demais lendas existentes, esta será uma lenda amazônica moderna, produto da agonia do capital e dos ajustes assumidos pelo governo, como os cortes no financiamento da educação, no intuito de superara crise econômica e recuperaras suas taxas de lucros.

\footnotetext{
${ }^{21} \mathrm{O}$ recorte por esse campus se deve a ainda não terem sido finalizadas as obras da moradia estudantil, e não terem sido iniciadas as obras do Restaurante Universitário. Dados extraídos das planilhas institucionais disponibilizadas pela gestão administrativa da UFAM.
} 


\section{Conclusões}

Após as análises de como foi previsto e aplicado o orçamento para a expansão da Universidade Federal do Amazonase das implicações com o objetivo quantitativo de acesso ao ensino superior, estimado pelo governo federal no Programa Reuni, buscamos registrar as primeiras sínteses possíveis, na mediação da realidade concreta da expansão da UFAM com a teoria produzida na área.

Nesse sentido, é possível afirmar que os cortes financeiros realizados pelo governo federal se constituem em fator determinante para a precarização da educação superior e para a não consolidação da expansão, realizada nos campi de Benjamin Constant, Coari, Humaitá, Itacoatiara e Parintins. Vale registrar que esse não é um fenômeno isolado à realidade da UFAM,mas que, reservadas as particularidades de cada universidade em expansão, vem ocorrendo na totalidade do próprio Reuni por todo o país.

Inserido o problema dos cortes na destinação orçamentária da UFAM na totalidade do programa deexpansão, é necessário compreender que essa totalidade cumpre com a agenda ditada pelo Banco Mundial e pelas demais agências multilaterais de financiamento, ao oferecer uma educação superior mínima, pautada sobre dados quantitativos de acesso, orientada pelo mercado e por isso preconizadora apenas de conhecimentos básicos necessários para o trabalho, e não para a formação humana.

A prioridade quantitativa do número de matrículas, segregada da qualidade da educação, cumpre com o projeto ampliado da sociedade do capital, lançado a partir da crise de 1970, quando o financiamento estatal das políticas públicas foi passando por ajustes, sendo reduzido, em detrimento de estratégias de atendimento aos setores privados, como a compra de vagas (que vem sendo realizada nas universidades privadas, para alunos que não conseguem adentrar as universidades públicas) e até mesmo a ampliação das linhas de crédito para o financiamento estudantil, ocorridas nos governos Lula e Dilma como continuidade do governo FHC, e agravados sem precedentes pelo governo Temer.Com o aprofundamento da crise econômica mundial, o governo Temer segue com a justificativa generalista já utilizada por Dilma para explicar os cortes orçamentários da educação como um todo e do programa de expansão, de forma particular.

A análise dialética desse objeto nos permite registrar que os cortes no orçamento não estão ocorrendo sem que as contradições se aflorem. Os servidores públicos das universidades federais realizaram duas importantes greves, em 2012 e em 2015, e seguem resistindo aos ataques.Nessas paralisações, a defesa da qualidade da educação e do caráter público da 
educação estão como prioridade na pauta de reivindicações, bem como a marcante posição contrária aos cortes no financiamento, ao congelamento dos investimentos,à não abertura de concursos públicos e a mais um pacote de cortes na Reforma da Previdência.

Além das contradições colocadas em nível nacional, no âmbito da UFAM, e em especial no trato com os campi de expansão, docentes, TAE e estudantes têm esses pontos como ordem do dia de suas reivindicações. Porém há que se destacar que, apesar de todos os esforços dessas organizações classistas, o governo está mais forte, em especial após o impeachment, e imprime para as universidades públicas o projeto neoliberal de financiamento, em especial na expansão, por já ter alcançado seu objetivo da oferta quantitativa de vagas - no caso da expansão da UFAM, totalizando 1.500 vagas.

O enfrentamento ao projeto precarizado de expansão necessita da adesão de todos os sujeitos históricos envolvidos com a educação, de uma política transitória, mediadora de lutas cada vez mais ampliadas, sem perder o foco da revolução mundial. Esta permitirá a superação das contradições pertinentes à educação, ao mesmo tempo em que a nova organização entre os homens para produzir e reproduzir sua existência carecerá de uma formação humana, no sentido da formação do ser humano omnilateral.

\section{Referências}

ANDRADE, Antonia Costa. Os governos FHC e Lula e a ressignificação do neodesenvolvimentismo: o Reuni. 2013. Tese (Doutorado em Educação) - Universidade Federal deUberlândia, Uberlândia, 2013.

ANTUNES, Ricardo Luiz Coltro. Os sentidos do trabalho: ensaios sobre a afirmação e a negação do trabalho. São Paulo: Boitempo, 2001.

ANTUNES, Ricardo Luiz Coltro. Adeus ao trabalho? Ensaio sobre as metamorfoses e a centralidade do mundo do trabalho. São Paulo: Cortez, 2003.

ANTUNES, Ricardo Luiz Coltro; SILVA, Maria Aparecida Moraes (orgs.). O avesso do trabalho.2. ed.São Paulo: Expressão Popular, 2010.

ARCARY, Valério. Um reformismo quase sem reformas: uma crítica marxista do governo Lula- em defesa da revolução brasileira. São Paulo: Instituto José Luís e Rosa Sundermann, 2011.

BANCO MUNDIAL. Prioridades e estratégias para a educação. Washington-DC: Banco Mundial, 1995.

BASTOS, Cristiane Pereira de Moraes. A corrosão do caráter público das universidades federais: influências do banco mundial no REUNI. 2009. Dissertação (Mestrado) Universidade Federal Fluminense, Niterói, 2009.

BRASIL. Lei de Diretrizes e Bases da Educação. Brasília: MEC, 1996.

BRASIL. Parâmetros Curriculares Nacionais. Ensino Médio. Brasília: MEC, 2000. 
BRASIL. Lei no 10.172/2001. Plano Nacional de Educação. Brasília: MEC, 2001.

BRASIL. Diretrizes Curriculares Nacionais para a Educação Básica. Brasília: MEC, 2003.

BRASIL. Decreto no 6.096/2007. Institui o Programa de Apoio a Planos de Reestruturação e Expansão das Universidades Federais - REUNI. Brasília: MEC, 2007.

BRASIL. Análise sobre a expansão das Universidades Federais de 2003-2012. Brasília: MEC, 2012.

BRASIL. Projeto de Emenda Constitucional 241. Brasília, 2016 a.

BRASIL. Portaria Normativa no 20, de 13 de outubro de 2016. Brasília: MEC, 2016 b.

CARNEVISKIS, Claudia; MACALINI, Edson; SILVA, Elizandra Garcia. A precarização do trabalho docente nas licenciaturas dos campi em expansão da Universidade Federal do Amazonas. In: SILVA, Maria Cristina; SANTOS, Vera Marques (orgs.). Formação docente e políticas públicas. Florianópolis: Letras Contemporâneas, 2016. p. 121-141.

COMPARATO, Fabio Konder. Significado e perspectivas da crise atual. Carta Maior, São Paulo, 8 nov. 2015. Disponível em: https://www.cartamaior.com.br/?/Editoria/PrincipiosFundamentais/Significado-e-perspectivas-da-crise-atual/40/34933. Acesso em: 16 out. 2016.

LEHER, Roberto. Educação no governo Lula da Silva: a ruptura que não aconteceu. In: MAGALHAES, João Paulo de Almeida et al. (orgs.). Os anos Lula: contribuições para um balanço crítico 2003-2010. Rio de Janeiro: Garamond, 2010. p. 369-412.

LIMA, Edileusa Esteves; MACHADO, Lucília Regina de Souza. Reuni e expansão universitária na UFMG de 2008-2012. 2016. Disponível em: http://www.scielo.br/scielo.php?pid=S217562362016000200383\&script=sci_abstract\&tlng=pt. Acesso em: 18 jul. 2016.

MANCEBO, Deise; VALE, Andréa Araujo; MARTINS, Tânia Barbosa. Políticas de expansão da educação superior no Brasil 1995-2010. Revista Brasileira de Educação, Rio de Janeiro, v. 20, n. 60, jan.-mar. 2015.

MARX, Karl. Manuscritos econômico-filosóficos e outros textos escolhidos. 2. ed. São Paulo: Abril Cultural, 1978.

MAUÉS, Olgaíses; SOUZA, Micheli Borges. A expansão da educação superior no Brasil e a política da formação de professores. 2015. Disponível em:

https://periodicos.ufpel.edu.br/ojs2/index.php/caduc/article/view/3823www.anped11.uerj.br. Acesso em: 22 nov. 2015.

MÉSZÁROS, Ístvan. Para além do capital: rumo a uma teoria da transição. São Paulo: Boitempo, 2002.

MÉSZÁROS, Ístvan. A educação para além do capital. São Paulo: Boitempo, 2008.

MORAES, Karine Nunes de. A produção acadêmica sobre a expansão da educação superior no Brasil no período de 1995 a 2010. Tese (Doutorado em Educação) - Programa de Pós-Graduação em Educação,Universidade Federal de Pernambuco,Recife, 2013.

MOURÃO, Arminda Rachel Botelho. A fábrica como espaço educativo. São Paulo: Scortecci, 2006.

NOZAKI, HajimeTakeuchi.Educação Física e reordenamento do mundo do trabalho:mediações da regulamentação da profissão. Tese (Doutorado em Educação) Universidade Federal Fluminense, Niterói, 2004. 
PAULA, Cristiana Maria de. Neoliberalismo e reestruturação da educação superior no Brasil: o REUNI como estratégia do governo Lula e da burguesia brasileira para subordinar a universidade federal a lógica do atual estágio de acumulação do capital. 2009. Dissertação (Mestrado em Educação) - Universidade Federal Fluminense, Niterói, 2009.

RAMOS,Marise. A pedagogia das competências. Petrópolis: Vozes, 2011.

ROMERO, Diego. Marx sobre as crises econômicas do capitalismo. São Paulo: José Luis e Rosa Sundermann, 2009.

SADER, Emir; GENTILI, Pablo (orgs.). O Pós-Neoliberalismo I: as políticas sociais e o Estado democrático. Rio de Janeiro: Paz e Terra, 1995.

SADER, Emir; GENTILI, Pablo (orgs.). Pós-neoliberalismo II: que Estado para que democracia? Petrópolis: Vozes, 1999.

SAVIANI, Demerval. A nova LDB: limites e perspectivas. Campinas: Autores Associados, 2007.

SILVA, Aurélio Ferreira da. O Reuni entre a expansão e a reestruturação: uma abordagem da dimensão acadêmico-curricular. 2014. Dissertação (Mestrado em Educação)- Universidade de São Paulo, São Paulo, 2014.

SOLANO, Cleonice Halferd; COSTA, Amanda Cristina Bastos. A formação social brasileira: implicações para as políticas educacionais na atualidade. In: ENCONTRO BRASILEIRO DE EDUCAÇÃO E MARXISMO, 5., 2011, Florianópolis. Anais[...] Florianópolis: UFSC, 2011.

UNIVERSIDADE FEDERAL DO AMAZONAS - UFAM. Cursos de graduação.

Disponível em: https://ufam.edu.br/pro-reitorias/pro-reitoria-de-planejamento-e-desenvolvimentoinstitucional-proplan. Acesso em: 20 dez. 2015a.

UNIVERSIDADE FEDERAL DO AMAZONAS - UFAM. LOA 2007. Disponível em: https://ufam.edu.br/pro-reitorias/pro-reitoria-de-planejamento-e-desenvolvimento-institucionalproplan. Acesso em: 20 dez. 2015b.

UNIVERSIDADE FEDERAL DO AMAZONAS - UFAM. LOA 2008. Disponível em: https://ufam.edu.br/pro-reitorias/pro-reitoria-de-planejamento-e-desenvolvimento-institucionalproplan. Acesso em: 20 out. 2016.

ZAGO, Nadir; PEREIRA, Tiago; PAIXÃO, Lea Pinheiro. Expansão do ensino superior: problematizando o acesso e a permanência de estudantes em uma nova universidade federal. In: REUNIÃO NACIONAL DA ANPED, 37., Florianópolis, 2015. Anais[...] Florianópolis: UFSC, 2015. 